\title{
Body weight misperception patterns and their association with health-related factors among adolescents in South Korea
}

\author{
Hyunjung Lim ${ }^{a, b}$ and Youfa Wang ${ }^{a}$ \\ aJohns Hopkins Global Center on Childhood Obesity, Center for Human Nutrition, Department of \\ International Health, Bloomberg School of Public Health, Johns Hopkins University, Baltimore, \\ MD 21205, USA \\ ${ }^{\mathrm{b}}$ Research Institute of Medical Nutrition, Department of Medical Nutrition, Kyung Hee University, \\ Seoul 130-701, Republic of Korea
}

\begin{abstract}
Objective-Examine body weight misperception and its association with health-related factors among South Korean adolescents.

Design and Methods-The 2009 Korea Youth Risk Behavior Web-based Survey data from 72,399 adolescents aged 12-18 years were used. Based on agreements between weight status assessed according to self-reported BMI and self-perceived weight status, adolescents were classified as weight underestimate, accurate, and overestimate. Logistic regression models examined the associations controlling for covariates.
\end{abstract}

Results-Over 50\% adolescents misclassified their own weight status: underestimation(23.4\%) and overestimation(26.8\%). Boys had a higher underestimation rate than girls(30.3\% vs. $15.6 \%)$ and a lower overestimation rate( $21.3 \%$ vs. $33.0 \%)$. In girls, overestimation was higher in highincome families and well-educated parents( $41.0 \%)$. Compared to those with accurate weight perception, participants who underestimated their weight were more likely to have an unhealthy diet as indicated by higher daily consumption( $\geq$ once/day) of fast food[OR=1.18(1.00,1.39)] and unhealthy snacks[OR=1.11(1.03,1.19)]. Girls who overestimated their weight had more screen time[ $\geq 2$ hours/day, OR=1.12(1.03,1.22)]. Participants who overestimated their weight were more likely to be stressed[OR=1.24(1.18,1.31)] and depressed[OR=1.18(1.21,1.25)].

Conclusions-Over half of Korean adolescents had misperception on own weight status, the rates varied by gender and socio-economic status. Weight misperception is associated with healthrelated outcomes compared to peers with accurate perceptions about own weight status.

\section{Keywords}

obesity; weight perception; eating; physical activity; psychological factors; adolescents; children

\section{Introduction}

Adolescence is a critical period for healthy growth and development, including the formation of lifestyles (1). Childhood obesity has become a global epidemic (2) and weight-

\footnotetext{
*Address correspondence to: Youfa Wang, M.D., M.S., Ph.D., Director, Johns Hopkins Global Center on Childhood Obesity, Department of International Health, Human Nutrition Program, Room E2546, Johns Hopkins Bloomberg School of Public Health, 615 North Wolfe Street, Baltimore, MD 21205, USA, Tel: 410502 3102, Fax: 410955 0196, ywang@jhsph.edu.

Conflicts of interest statement

The authors declared no conflict of interest.
} 
related concerns have increased among adolescents (3-5). In addition, cultural beliefs and beauty ideals are changing, resulting in ever-increasing peer pressure on young female adolescents $(6,7)$. Some research reported increased rates of adolescents' weight misperception $(6,8-10)$. Weight misperception patterns vary depending on gender, ethnicity, socioeconomic status (SES), cultural and behavioral factors $(9,11-15)$.

Body weight misperception has been associated with body image dissatisfaction, unhealthy weight control practices, depression, and low self-esteem (3,16-19). In extreme cases, it may be more likely to cause eating disorders and even suicidal ideation $(6,20)$. However, limited previous studies have tested the relationship between weight perception and healthrelated factors such as eating and physical activity patterns $(9,21)$.

Since South Korea became industrialized, global media and the internet have become common sources of information and exposure. Previous Korean studies about perceived weight status were not analyzed with respect to the health-related factors in relation to weight perception status $(10,20)$. Therefore, understanding weight misperception patterns among Korean adolescents and their association with health-related factors can provide important insights for public health policy and clinical treatment for individual adolescents.

We investigated the body weight status misperception patterns based on self-reported data among adolescents by gender and SES, and the differences in weight perception patterns according to socio-demographics and lifestyles using recent nationally representative data collected in Korea. Further, we examined the associations between weight perception and health-related psychological outcomes. Our hypothesis was that those with misperceptions on own weight status might have undesirable health-related psychological outcomes (e.g., those overweight adolescents who mistakenly thought they had normal weight might be more likely to have unhealthy eating behaviors compared to their counterparts).

\section{METHODS AND PROCEDURES}

\section{Study population and database}

The data were derived from the Fifth Korea Youth Risk Behavior Web-based Survey (KYRBS), administered by the Korea Center for Disease Control and Prevention from September to November, 2009. The KYRBS is a self-administered, anonymous, online survey comprising 129 questions in 14 categories, including obesity, physical activity, and health equity (22). In the $2009 \mathrm{KYRBS}, 76,937$ students based in 400 middle schools and 400 high schools were randomly selected to participate. Each student was randomly assigned a unique identification number, which they used to log into the survey webpage in the computer room of their school. Before they began the questionnaire, an item asked potential respondents to electronically indicate whether they agreed to participate or not. Those who declined to participate did not proceed further, 75,066 students (39,612 boys and 35,454 girls) agreed to participate (response rate: $97.6 \%$ ) with complete demographic data (22). Subjects who did not provide weight and height information $(n=2,667)$ were excluded from our analysis, resulting in 72,399 subjects (38,152 boys; 34,247 girls) aged 12 to 18 years being included in this study.

\section{Data collection and key measurements}

\section{Classification of overweight and obesity based on self-reported weight and}

height—Body mass index (BMI=weight $[\mathrm{kg}] / \mathrm{squared}$ height $\left[\mathrm{m}^{2}\right]$ ) was calculated based on self-reported weight and height. We used the 2007 Korean National Growth Charts (23). BMI percentile to assess their weight status: a) underweight, BMI <5th percentile; b) overweight, 85 th percentile $\leq$ BMI $<95$ th percentile; and c) obese, BMI $\geq 95$ th percentile. 
Due to the relatively small sample size, we combined overweight and obese groups in the analysis.

Self-reported weight and height are likely to suffer from measurement errors and bias (24). Nevertheless, self-reported BMI is used widely and some studies have shown a reasonable validity compared to measured BMI in representative samples of several populations such as Japan (25), and the US (26). A previous study also reported an acceptable validity of selfreported weight status using KYRBS (27): sensitivity (69\%), specificity (100\%), and Kappa $(0.8$, indicates an excellent agreement) (27).

Classification of body weight misperception-Body weight status misperception was determined according to the agreement between BMI categories based on reported weight and height (coded as 1, 2, and 3 for underweight, normal, and overweight, respectively) and their perceptions about their own weight status, which were assessed through the question: "How do you describe your weight?" The response options for the question were "very underweight," "slightly underweight," "about the right weight," "slightly overweight," and "very overweight". The answer was reclassified into three categories (coded as 1, 2, and 3 for underweight, normal, and overweight, respectively). Based on those agreements, participants were classified into concordant weight perception (here after referred to as "accurate") and discordant weight perceptions (here after referred to as "weight misperception"). Individuals who reported their perceived weight status at least one category above their BMI categories were classified as overestimators; for underestimators, those at least one category above.

Family socioeconomic status (SES) - SES was defined by a combination of family income and parental education level based on adolescents' self-reported family income and parental education. Parental education and household income have been widely used to measure children's SES (28). The participants chose one among five family income levels: low, low-middle, middle, middle-high and high income. Then, the answer was reclassified into three categories: low (low or low-middle), middle, high (middle-high or high) income. Three parental education groups: both parents had <high school education (HS; 12 years), one parent had $\geq$ college education, both parents had $\geq$ college education. Next, we defined nine income-education groups, but only reported the results for three combinations: lowincome and low-education ("very low SES"), middle-income and middle-education ("middle SES") and high-income and high-education ("very high SES").

Smoking and drinking-Cigarette smoking and alcohol consumption were assessed by asking: "Have you ever tried cigarette smoking/drinking alcohol, even once?" If the answer was "yes," a follow-up question asked, "During the past 30 days, on how many days did you smoke cigarettes/drink alcohol?" Those who responded "more than one day" were classified as the group engaged in smoking and drinking.

Eating patterns-Eating patterns were assessed by eight questions, e.g., about frequency of having breakfast and the frequency of eating fruits, vegetables, milk, sugar sweetened beverages, fast foods (Most common, largest, top sales or specific fast food chainshamburgers, pizzas, hot-dogs, French fries, onion rings, chicken nuggets), instant noodles, or unhealthy snacks over the past 7 days. Each item was reclassified as a dichotomized variable (desired vs. unhealthy eating pattern) for the analyses (desired eating pattern variables were having breakfast [ $\geq 3$ days/week], eating fruits and vegetables, as well as milk intake [ $\geq$ once/day], and consumption of sugar sweetened beverages, fast foods, instant noodles, and unhealthy snacks, e.g., cookies, candy, and biscuit intake [< once/day]). 
Physical activity-Physical activity was assessed through asking seven questions, including questions about regular exercise, walking, screen time every day over 2 hours (e.g., watching TV or playing video games/internet): "On how many days of the past 7 days, did you do at least 20 minutes of exercise hard enough to make you sweat and breathe hard?", "On how many days of the past 7 days, did you do at least 30 minutes of moderate exercise that was not hard enough to make you sweat or breathe hard?", "During the past 7 days, on how many days were you strengthening exercise?", "On an average school day, how many hours do you watch TV or video, or play computer or video games in your leisure time?" Each item was reclassified as dichotomized variables (desired vs. low levels of physical activity) for the analyses (as desired physical activity variables: vigorous exercise [ $\geq 3$ days/week], moderate exercise [ $>3$ days/week], strengthening exercise [ $\geq 3$ days/week], walking [ $230 \mathrm{~min} /$ day], or screen time [ $<2 \mathrm{hrs} /$ day] $)$.

Psychological factors: stress or depressed mood-The adolescents who felt severe stress, as determined by their answer to the question "How much stress do you usually feel?", were placed in the perceived stress group based on answers indicating "too much stress" and "slightly too much stress." Depressed mood was measured by a yes-no question: "During the past 12 months, did you ever feel so sad or hopeless for two weeks or more in a row that you stopped doing some usual activities?"

\section{Statistical analysis}

We described the weight perception rate by gender and SES. Then we tested trends across SES categories. Weighted kappa with 95\% confidence intervals (CI) was calculated to measure agreement between reported and perceived body weight status. A kappa of 0.410.60 indicates "moderate" agreement and $0.21-0.40$ indicates "fair" agreement (29). The relationships between weight perception and reported weight status were measured using the Kendall's Tau-b correlation coefficient. In addition, the differences of socio-demographic and life style factors within each weight status were tested using $\chi^{2}$ tests.

Finally, we fitted logistic regression models to examine the association between weight misperceptions (e.g., underestimated and overestimated as exposure variables; accurate as a reference group) and health-related factors (e.g., diet, physical activity, stress, and depressed mood as outcome variables). The reference group consisted of each most desired or healthy behavior or condition. All models were controlled for age, gender, BMI, residence region, and combined SES.

All analyses were two-tailed and a $P$-value $<0.05$ was considered statistically significant. The primary sampling units (school), strata, and sampling weights were taken into account using SAS release 9.2 survey-related procedures (SAS Institute, Inc. Cary, NC, USA). This gave nationally representative estimates and a correct estimate of the related variances.

\section{RESULTS}

\section{Body weight perception by gender and SES}

Participants who accurately perceived their weight status were $48.4 \%$ boys and $51.4 \%$ girls; however, misperception patterns differed by gender (Figure 1A). More boys underestimated their weight status $(30.3 \%)$ than did girls $(15.6 \%)$, while fewer boys overestimated their status compared to girls (21.3\% vs. $33.0 \%)$. We found difference in SES, based on a combination of family income and parental education level, by weight perception (Figure 1B, 1C, and 1D). Compared to the low-income and low-education ("very low SES") group, the high-income and high-education ("very high SES") group was more likely to overestimate their weight status $(23.9 \%$ in very low SES vs. $29.5 \%$ in very high SES; trend 
test, $\mathrm{P}<0.0001)$. There was a big gap between genders. In particular, a large proportion $(41.0 \%)$ of very high SES girls overestimated their weight, while their underestimation rate (14.9\%) was the lowest among the three SES groups $(\mathrm{P}<0.0001)$. In addition, the overall proportion of weight overestimation tended to increase along with SES, and the proportion of both accurate weight perception and underestimation of weight decreased (trend test, $\mathrm{P}<0.05)$.

\section{Agreement between reported weight status and self-perceived body weight status}

Based on reported weight and height, $11.7 \%$ of the total participants were actually overweight or obese (13.5\% of boys vs. $9.6 \%$ of girls). However, $37.6 \%$ of all participants considered themselves to be overweight or obese. Table 1 shows the percentages of agreement among those who judged their own weight status correctly. It shows a $49.9 \%$ agreement, overall. Weighted kappa indicated a fair agreement $(0.32$ in boys and 0.30 in girls). All Kendall's tau-b rank-order correlation coefficients were highly significant $(\mathrm{p}<0.0001)$.

\section{Socio-demographic and lifestyle characteristics by weight perception}

In the underestimating group, the rates of boys and middle school students were higher than those of their counterparts $(\mathrm{P}<0.05)$. Most of the underestimating subjects $(98.7 \%)$ had a normal weight, and only $1.3 \%$ of them was overweight $(\mathrm{P}<0.0001)$. About a fifth of the weight-underestimating subjects had tried to gain weight. Interestingly, about $42 \%$ of underestimating subjects had highly educated parents. The proportions of alcohol drinkers and smokers were $21.7 \%$ and $15.1 \%$, respectively, in the underestimating group $(\mathrm{P}<0.0001)$.

The rate of girls overestimating their weight (57.9\%) was higher than that of overestimating boys $(42.1 \%)$. Participants who overestimated their weight were actually underweight $(2.8 \%)$ or normal weight $(97.2 \%)$. Overweight subjects, however, did not overestimate their weight status. There was a clear difference of reported weight control practices in the overestimation group. Participants who reported trying to lose weight were $48.3 \%$ in the overestimation group; whereas, $0.9 \%$ of the overestimation group reported trying to gain weight $(\mathrm{P}<0.0001)$. Unlike the weight-underestimating group, about $44 \%$ of overestimating subjects have less-educated parents. The overestimation group had approximately $20 \%$ who were alcohol drinkers and about $10 \%$ who were smokers $(\mathrm{P}<0.0001$ in each case).

\section{Associations between weight misperception and eating and physical activity}

Table 3 shows that underestimation of weight was associated with having breakfast $<3$ days per week for girls $(\mathrm{OR}=1.15 ; 95 \% \mathrm{CI}=1.05,1.27)$. Compared with adolescents who perceived their weight status accurately, the underestimating group was more likely to consume fast foods $(\mathrm{OR}=1.18 ; 95 \% \mathrm{CI}=1.00,1.39)$ and unhealthy snacks at least once a day $(\mathrm{OR}=1.11 ; 95 \% \mathrm{CI}=1.03,1.19)$, whereas the overestimating group was less likely to drink sugar sweetened beverages at least once a day $(\mathrm{OR}=0.90 ; 95 \% \mathrm{CI}=0.82,1.00)$. After stratification by gender, however, there is no association with eating patterns among either boys or girls in the weight-overestimation group.

There was gender difference regarding physical activity. Boys who overestimated their weight were less likely to exercise regularly. Girls who overestimated their weight were more likely to participate in vigorous exercise, but also more likely to have screen time $\geq 2 \mathrm{~h} /$ day $(\mathrm{OR}=1.12 ; 95 \% \mathrm{CI}=1.03,1.22)$ than those with perceiving accurate weight status.

\section{Associations between weight misperception and reported stress and depressed mood}

After controlling for age, reported BMI, residence region, and combined SES, we found an association between weight underestimation and stress status, especially in boys (Table 3). 
In addition, our results show relatively strong associations between weight overestimation and stress or depressed mood. The group that overestimated their weight had high stress $(\mathrm{OR}=1.24 ; 95 \% \mathrm{CI}=1.14,1.36$ in boys and $\mathrm{OR}=1.24 ; 95 \% \mathrm{CI}=1.17,1.32$ in girls $)$ and were more likely to feel depressed $(\mathrm{OR}=1.12 ; 95 \% \mathrm{CI}=1.04,1.21$ in boys and $\mathrm{OR}=1.23 ; 95 \%$ $\mathrm{CI}=1.15,1.32$ in girls).

\section{DISCUSSION}

Based on the 2009 nationally representative data in Korea, half (51.6\% of boys; $48.6 \%$ of girls) of the adolescents did not have a correct perception of their own weight status. Sixty percent of normal-weight participants misperceived their own weight status. A big gender difference in the misperception patterns existed. In girls, one-third overestimated their weight, particularly s in the high SES group; while over a quarter of boys underestimated their weight status. Regarding health-related factors, those who underestimated their weight was more likely to consume fast foods and unhealthy snacks. Boys that overestimated their weight status exercised less than those who accurately perceived. Girls who overestimated did more vigorous exercise, but had more screen time. Weight overestimation is strongly associated with stress and depressed moods.

Previous studies examined weight misperception patterns among adolescents in different populations $(4,7,9,10,30-32)$. Studies in Asian countries, such as mainland China, Hong Kong, and Malaysia, showed that weight misperception rates vary between $34.1 \%$ and $74.3 \%$, depending on age, gender, and populations $(7,9,10,30)$. These figures were $46.0 \%$ in US adolescents (31), 40.0\% in young Dutch adolescents (32), and about $45.0 \%$ (47.4\% of boys and $44.2 \%$ of girls) in six different central-eastern European countries (Hungary, Slovakia, Czech Republic, Romania, Ukraine, Poland) (4). For example, a previous US study of African-American adolescents (14) showed $67.2 \%$ correctly judged their weight status, $27.2 \%$ underestimated it, and only $5.6 \%$ overestimated their weight status (14). The difference between findings in this study and other studies might be due to ethnic differences or the higher overweight prevalence rate in the US (39.8\% in the AfricanAmerican subjects (14) vs. 11.7\% in our subjects). A study based on US adolescents with normal weight reported a lower overestimating rate (16.2\%), which was low compared to our result (5). Our study found a gender difference in weight misperception patterns. Compared to boys, more girls overestimated and less girls underestimated their own weight status. This was in accordance with previous studies $(4,9,10)$.

Several controversial studies have been conducted on the relation of SES, such as parents' education $(9,33)$ and income $(34,35)$, on weight perception. For example, unlike our results, a study using US representative data has shown that there was no significant association between weight misperception and poverty-income ratio as an indicator of adolescents' SES (35). Chinese girls who had highly educated parents were less likely to misperceive themselves as being overweight (9). However, household income was highly positively related to body size misperception in black US men and women, but not in white men and women (34). Another study that reported on high SES related to weight misperception (36) had results that were consistent with our findings, in particular as regards high SES related to high misperception among girls.

In the present study, the rates of drinking alcohol (21.1\%) and smoking (12.6\%) were relatively low compared to those in US adolescents ( $24.2 \%$ and $19.5 \%$, respectively) (37). However, daily smoking rate in Korean adolescents increased from 3.9\% in 2005 to $6.7 \%$ in 2009 (38). An earlier Chinese study suggested that the weight misperception rate of alcohol drinkers and smokers was higher than their counterparts in adolescents (9), which is similar to our results. Research regarding eating and physical activity behaviors according to their 
weight-perception status is limited. There are a few related studies for Chinese (9) and African-American (21) adolescents. For example, African-American girls who overestimated their weight (e.g., had a smaller ideal body image) had unhealthy eating habits, such as consuming fewer fruits and drinking less milk. However, boys who underestimated their weight (e.g., had a larger ideal body image) were less likely to eat snacks (21). In a previous study based on US nationally representative data, both boys and girls with accurate weight perception had healthy weight-related behaviors, such as more fruit and vegetable consumption and physical activity than the misperceivers (26). In short, having an accurate weight perception affects adolescents' correct self-assessment of their dietary habits (26), which means it may help in the formation of a healthy lifestyle and foster appropriate development.

We found that adolescents who underestimated their weight were more likely to consume fast foods and unhealthy snacks. However, there were no significantly associated eating patterns found among overestimating girls. Girls who overestimated their weight status might be more likely to choose unhealthy dieting methods, such as taking diet pills, fasting, or using laxatives to lose their weight. Weight misperceivers among Korean girls need be empowered to correct their perception and be provided with appropriate education focused on improving eating patterns with considerations of their growth and development.

Our study also confirmed the association between weight misperception and physical activity and showed gender difference. This might be affected by mass media or be a social issue in Korea. Nowadays, the ideal body image derived from the mass media has fixated on skinny women and muscular men. Therefore, underestimating boys did seem to exercise in order to develop muscles, while overestimating girls were more likely to participate in vigorous exercise to lose weight. Proper exercise education programs for adolescents should focus on healthy growth and development rather than on body appearance. We also found that weight misperception, in particular overestimation, was related to psychological outcomes such as stress. Several previous studies $(8,19,39)$ reported weight overestimation being positively associated with anxiety/depression (19), psychological distress symptoms (39), and reported stress (8). Weight overestimation may also affect emotional development, academic achievement, severe eating disorder, and suicidal thoughts and behavior. To prevent these risks, comprehensive interventions to help correct weight misperception are needed, targeting the young people and their home, school, and community. Such programs might include regular BMI screening and reporting to children and their parents, checking up on weight perception status, health education, and individual counseling.

Our study has many strengths. We used recent nationally representative data. Our analysis took into account the complex sampling design effect to provide representative estimates. The participants' socio-demographic and economic information as well as health-related factors such as eating, physical activity patterns, and psychological factors were included. This is one of the few studies that have tested the association between weight perception and health-related factors.

This study also has some limitations. Self-reported data on weight and height and family SES were used in our study. Such data are likely to have measurement errors or bias, although they are valuable (24). Some research shows that self-reported data are likely to result in overestimation of height and underestimation of weight $(24,27)$ and self-reported BMI is slightly lower than measured BMI (25). Note that a study has examined the validity of self-reported weight and height in KYRBS and found acceptable sensitivity, specificity, and agreement comparing self-reported and measured values (27). Other potential biases in self-reported data such as socioeconomic status, eating habits, physical activity, and 
psychological factors may exist, despite there being many reliability tests (40). In addition, our cross-sectional study design cannot test causality.

In conclusion, weight misperception is common in adolescents in Korea. It compromises their health and development. Half of South Korean adolescents misperceived their weight status, which varied by gender and family SES. There was a consistent association between weight misperception and unhealthy eating patterns, e.g., the consumption of sugar sweetened beverages, fast food, and snacks, along with physical activity, stress and depressed mood. Health professionals and related government agencies need to develop comprehensive intervention programs to empower young people to have accurate weight status perception and maintain healthful eating and physical activity patterns and good mental health.

\section{Acknowledgments}

The study in part was supported by the NIH U54 HD070725. The contributions of the authors H.L. designed the study, acquired and analyzed the data, interpreted the results, and drafted the manuscript; Y.W. designed the study, guided the data analysis, interpreted the results, and revised the manuscript. All authors were involved in writing the paper and had final approval of the submitted and published versions.

\section{References}

1. Cooke R, Sawyer SM. Eating disorders in adolescence. An approach to diagnosis and management. Aust Fam Physician. 2004; 33:27-31. [PubMed: 14988957]

2. Wang Y, Lobstein T. Worldwide trends in childhood overweight and obesity. Int J Pediatr Obes. 2006; 1:11-25. [PubMed: 17902211]

3. Ali MM, Fang H, Rizzo JA. Body weight, self-perception and mental health outcomes among adolescents. J Ment Health Policy Econ. 2010; 13:53-63. [PubMed: 20919592]

4. Page RM, Ihasz F, Uvacsek M, Kalabiska I, Johnson E, Hantiu I, et al. Self-perception of body weight, weight management practices and goals, and other weight-related factors in central and eastern European adolescents. Int Q Community Health Educ. 2006; 27:39-58. [PubMed: 18039628]

5. Talamayan KS, Springer AE, Kelder SH, Gorospe EC, Joye KA. Prevalence of overweight misperception and weight control behaviors among normal weight adolescents in the United States. Scientific World Journal. 2006; 6:365-373. [PubMed: 16565773]

6. Chisuwa N, O'Dea JA. Body image and eating disorders amongst Japanese adolescents. A review of the literature. Appetite. 2010; 54:5-15. [PubMed: 19941921]

7. Lee S, Lee AM. Disordered eating in three communities of China: a comparative study of female high school students in Hong Kong, Shenzhen, and rural Hunan. Int J Eat Disord. 2000; 27:317327. [PubMed: 10694718]

8. Lo WS, Ho SY, Mak KK, Wong YM, Lai YK, Lam TH. Prospective effects of weight perception and weight comments on psychological health among Chinese adolescents. Acta Paediatr. 2009; 98:1959-1964. [PubMed: 19673720]

9. Xie B, Chou CP, Spruijt-Metz D, Reynolds K, Clark F, Palmer PH, et al. Weight perception and weight-related sociocultural and behavioral factors in Chinese adolescents. Prev Med. 2006; 42:229-234. [PubMed: 16458956]

10. Lee G, Ha Y, Vann JJ, Choi E. Weight perception and dieting behavior among Korean adolescents. J Sch Nurs. 2009; 25:427-435. [PubMed: 19351965]

11. Bergstrom R, Neighbors C. Body Image Disturbance and The Social Norms Approach: An Integrative Review of the Literature. Journal of Social and Clinical Psychology. 2006; 25:9751000 .

12. Martin MA, Frisco ML, May AL. Gender and race/ethnic differences in inaccurate weight perceptions among U.S. adolescents. Womens Health Issues. 2009; 19:292-299. [PubMed: 19733799] 
13. Nolan L, Grigorenko A, Thorstensson A. Balance control: sex and age differences in 9- to 16-yearolds. Dev Med Child Neurol. 2005; 47:449-454. [PubMed: 15991864]

14. Wang Y, Liang H, Chen X. Measured body mass index, body weight perception, dissatisfaction and control practices in urban, low-income African American adolescents. BMC Public Health. 2009; 9:183. [PubMed: 19523206]

15. Viner RM, Haines MM, Taylor SJ, Head J, Booy R, Stansfeld S. Body mass, weight control behaviours, weight perception and emotional well being in a multiethnic sample of early adolescents. Int J Obes (Lond). 2006; 30:1514-1521. [PubMed: 16718286]

16. Lee K, Sohn H, Lee S, Lee J. Weight and BMI over 6 years in Korean children: relationships to body image and weight loss efforts. Obes Res. 2004; 12:1959-1966. [PubMed: 15687397]

17. Seo DC, Jiang N. Associations between smoking and extreme dieting among adolescents. J Youth Adolesc. 2009; 38:1364-1373. [PubMed: 19779812]

18. Strauss RS. Self-reported weight status and dieting in a cross-sectional sample of young adolescents: National Health and Nutrition Examination Survey III. Arch Pediatr Adolesc Med. 1999; 153:741-747. [PubMed: 10401809]

19. ter Bogt TF, van Dorsselaer SA, Monshouwer K, Verdurmen JE, Engels RC, Vollebergh WA. Body mass index and body weight perception as risk factors for internalizing and externalizing problem behavior among adolescents. J Adolesc Health. 2006; 39:27-34. [PubMed: 16781958]

20. Kim DS, Cho Y, Cho SI, Lim IS. Body weight perception, unhealthy weight control behaviors, and suicidal ideation among Korean adolescents. J Sch Health. 2009; 79:585-592. [PubMed: 19909422]

21. Chen X, Wang Y. Is ideal body image related to obesity and lifestyle behaviours in African American adolescents? Child Care Health Dev. 2011; 38:219-228. [PubMed: 21434968]

22. Korea Centers for Disease Control and Prevention. The 5th Korea Youth Risk Behavior WebBased Survey. Seoul, South Korea: Korea Centers for Disease Control and Prevention; 2010.

23. Moon JS, Lee SY, Nam CM, Choi JM, Choe BK, Seo JW, et al. 2007 Korean national growth charts: review of developmental process and an outlook. Korean J Pediatr. 2008; 51:1-25.

24. Sherry B, Jefferds ME, Grummer-Strawn LM. Accuracy of adolescent self-report of height and weight in assessing overweight status: a literature review. Arch Pediatr Adolesc Med. 2007; 161:1154-1161. [PubMed: 18056560]

25. Yoshitake N, Okuda M, Sasaki S, Kunitsugu I, Hobara T. Validity of self-reported body mass index of Japanese children and adolescents. Pediatr Int. 2012; 54:397-401. [PubMed: 22168382]

26. Edwards NM, Pettingell S, Borowsky IW. Where perception meets reality: self-perception of weight in overweight adolescents. Pediatrics. 2010; 125:e452-458. [PubMed: 20142281]

27. Bae J, Joung H, Kim JY, Kwon KN, Kim Y, Park SW. Validity of self-reported height, weight, and body mass index of the Korea Youth Risk Behavior Web-based Survey questionnaire. Journal of preventive medicine and public health = Yebang Uihakhoe chi. 2010; 43:396-402. [PubMed: 20959710]

28. West P, Sweeting H. Evidence on equalisation in health in youth from the West of Scotland. Soc Sci Med. 2004; 59:13-27. [PubMed: 15087139]

29. Viera AJ, Garrett JM. Understanding interobserver agreement: the kappa statistic. Fam Med. 2005; 37:360-363. [PubMed: 15883903]

30. Khor GL, Zalilah MS, Phan YY, Ang M, Maznah B, Norimah AK. Perceptions of body image among Malaysian male and female adolescents. Singapore Med J. 2009; 50:303-311. [PubMed: 19352576]

31. Martin MA, May AL, Frisco ML. Equal weights but different weight perceptions among US adolescents. J Health Psychol. 2010; 15:493-504. [PubMed: 20460406]

32. Jansen W, van de Looij-Jansen PM, de Wilde EJ, Brug J. Feeling fat rather than being fat may be associated with psychological well-being in young Dutch adolescents. J Adolesc Health. 2008; 42:128-136. [PubMed: 18207090]

33. Guven A, Odaci H, Ozgen IT, Bek Y. Effects of individual factors on adolescent obesity: study in Turkey. Pediatr Int. 2008; 50:356-362. [PubMed: 18533952] 
34. Lynch E, Liu K, Spring B, Hankinson A, Wei GS, Greenland P. Association of ethnicity and socioeconomic status with judgments of body size: the Coronary Artery Risk Development in Young Adults (CARDIA) Study. Am J Epidemiol. 2007; 165:1055-1062. [PubMed: 17327218]

35. Yan AF, Zhang G, Wang MQ, Stoesen CA, Harris BM. Weight perception and weight control practice in a multiethnic sample of US adolescents. South Med J. 2009; 102:354-360. [PubMed: 19279513]

36. Wardle J, Griffith J. Socioeconomic status and weight control practices in British adults. J Epidemiol Community Health. 2001; 55:185-190. [PubMed: 11160173]

37. Eaton DK, Kann L, Kinchen S, Shanklin S, Ross J, Hawkins J, et al. Youth Risk Behavior Surveillance - United States, 2009. Morbidity and Mortality Weekly Report. 2010; 59:1-142. [PubMed: 20075837]

38. Korea Centers for Disease Control and Prevention. Korea Youth Risk Behavior Web-based Survey. Vol. 2010. Seoul, South Korea: Korea Centers for Disease Control and Prevention; 2009. Statistics from the fifth.

39. Xie B, Chou CP, Spruijt-Metz D, Reynolds K, Palmer PH, Wu Q, et al. Longitudinal analysis of weight perception and psychological factors in Chinese adolescents. Am J Health Behav. 2011; 35:92-104. [PubMed: 20950162]

40. Rey-Lopez JP, Ruiz JR, Ortega FB, Verloigne M, Vicente-Rodriguez G, Gracia-Marco L, et al. Reliability and validity of a screen time-based sedentary behaviour questionnaire for adolescents: The HELENA study. Eur J Public Health. 2012; 22:373-377. [PubMed: 21498560] 


\section{What is already known about this subject}

- Body weight misperception (underestimation and overestimation) is common and the rate has increased among adolescents in some countries, in particular based on studies from the U.S.

- Weight misperception patterns vary depending on gender, ethnicity, socioeconomic status, social, cultural and behavioral factors.

- Body weight misperception is associated with unhealthy weight control practices and low self-esteem.

\section{What this study adds}

- How's the situation in a non-Western population, South Korea based on nationally representative data from a large sample. Half (51.6\% of boys; $48.6 \%$ of girls) of South Korean adolescents misperceived their weight status, which varied by gender and family socioeconomic status; $60 \%$ of the normal-weight adolescents misperceived their own weight status. In girls, one-third overestimated their body weight, particularly in the high socioeconomic status group. Over a quarter of boys underestimated their weight status.

- Body weight misperception was associated with some undesirable eating and physical activity patterns. Compared to those perceived own weight status accurately, those underestimated were more likely to consume fast foods and unhealthy snacks; boys that overestimated own weight status exercised less; Girls who overestimated did more vigorous exercise, but had more screen time.

- Weight overestimation was strongly associated with stress and depressed moods. 


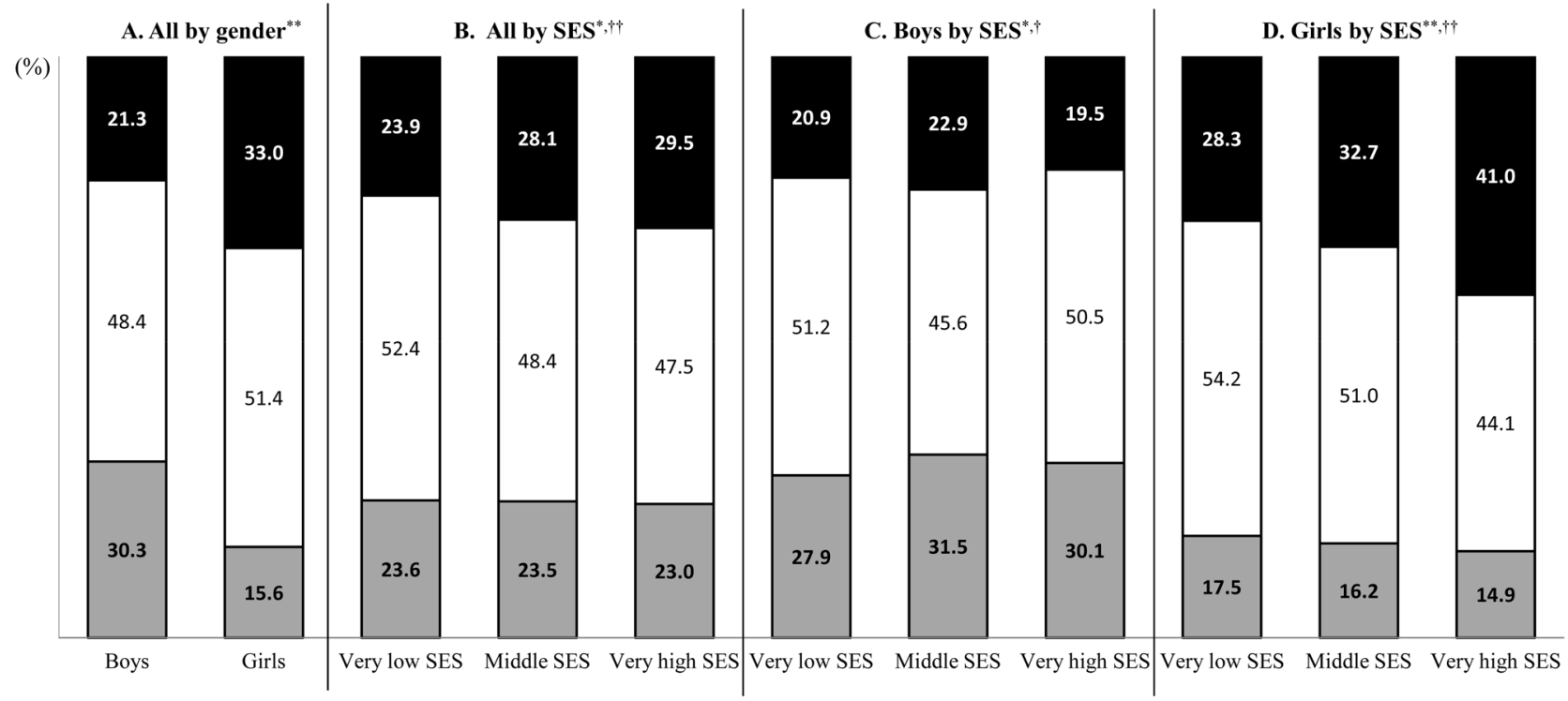

Figure 1.

Comparison of body weight perception by gender and socioeconomic status among South Korean adolescents ${ }^{\text {a }}$

KYRBS, Korea Youth Risk Behavior Web-based Survey

a Socioeconomic status (SES) was defined based on a combination of family income and parental education level. We used 3 family income groups: low, middle, and high income; and three education groups: both parents < high school education (HS; 12 years), one of their parents > college education, both parents > college education. Next, we defined 9 income-education groups, but have only presented the results for 3 combinations, namely, low-income and low-education ("Very low SES"), middle-income and middle-education ("middle SES") and high-income and high-education ("Very high SES").

$* P<0.001$ and $* * P<0.0001$ between-group difference was significant.

${ }^{\dagger} P$-trend $<0.001$ and ${ }^{\dagger \dagger} P$-trend $<0.0001$ across socioeconomic status. 


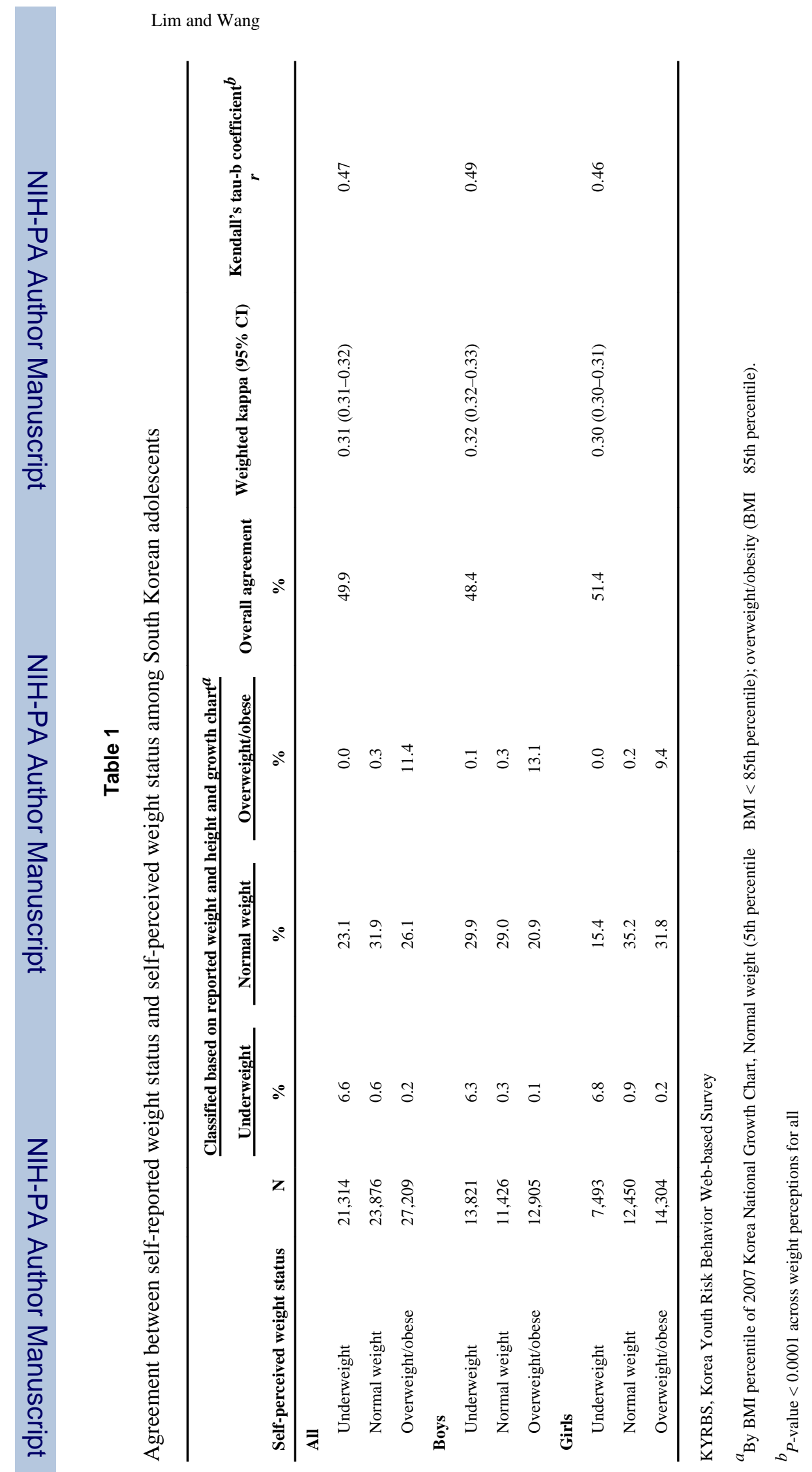

Obesity (Silver Spring). Author manuscript; available in PMC 2014 December 01. 
Table 2

Proportion of socio-demographic and lifestyle characteristics by body weight perception among South Korean adolescents

\begin{tabular}{|c|c|c|c|c|}
\hline & $\mathbf{N}$ & Underestimate $P$ & Accurate $P$ & Overestimate $P$ \\
\hline All & 72,399 & 23.4 & 49.8 & 26.8 \\
\hline \multicolumn{5}{|l|}{ Gender } \\
\hline Boys & 38,152 & $68.5 * * *$ & 48.6 & $42.1 * * *$ \\
\hline Girls & 34,247 & 31.5 & 51.4 & 57.9 \\
\hline \multicolumn{5}{|l|}{ School } \\
\hline Middle school students & 37,157 & $53.2 * *$ & 49.9 & 49.6 \\
\hline High school students & 35,242 & 46.8 & 50.1 & 50.4 \\
\hline \multicolumn{5}{|l|}{ Weight status ${ }^{a}$} \\
\hline Underweight & 5,214 & $0.0 * * *$ & $13.2 * * *$ & $2.8 * * *$ \\
\hline Normal weight & 58,602 & 98.7 & 64.1 & 97.2 \\
\hline Overweight & 8,583 & 1.3 & 22.8 & 0.0 \\
\hline \multicolumn{5}{|c|}{ Try to do about body weight } \\
\hline Nothing & 36,926 & $64.2 * * *$ & $50.2 * * *$ & $40.7 * * *$ \\
\hline Lose weight & 23,373 & 11.2 & 33.5 & 48.3 \\
\hline Gain weight & 4,692 & 16.2 & 4.8 & 0.9 \\
\hline Stay the same & 7,408 & 8.4 & 11.5 & 10.0 \\
\hline \multicolumn{5}{|l|}{ Drinking alcohol } \\
\hline Yes & 15,242 & $21.7 * * *$ & $20.5 * * *$ & 20.8 *** \\
\hline No & 57,157 & 78.3 & 79.5 & 79.2 \\
\hline \multicolumn{5}{|l|}{ Smoking } \\
\hline Yes & 9,155 & $15.1 * * *$ & $12.0 * * *$ & $11.1 * * *$ \\
\hline No & 63,244 & 84.9 & 88.0 & 88.9 \\
\hline \multicolumn{5}{|l|}{ Residence } \\
\hline Urban & 37,960 & $54.4 * * *$ & $54.4 * * *$ & $55.3 * * *$ \\
\hline Suburban & 25,456 & 40.1 & 40.1 & 39.9 \\
\hline Rural & 8,983 & 5.5 & 5.5 & 4.9 \\
\hline \multicolumn{5}{|l|}{ Family income ${ }^{b}$} \\
\hline High & 18,396 & $29.7 * * *$ & $28.4 * * *$ & $27.1 * * *$ \\
\hline Middle & 34,488 & 46.1 & 47.9 & 47.6 \\
\hline Low & 19,515 & 24.2 & 23.7 & 25.3 \\
\hline \multicolumn{5}{|l|}{ Parental education ${ }^{c}$} \\
\hline High & 16,599 & $41.9 * * *$ & $45.0 * * *$ & $32.0 * * *$ \\
\hline Middle & 13,140 & 24.4 & 23.0 & 24.4 \\
\hline Low & 26,530 & 33.6 & 32.0 & 43.6 \\
\hline
\end{tabular}

KYRBS, Korea Youth Risk Behavior Web-based Survey

${ }^{a}$ Based on self-reported weight and height by 2007 Korea growth chart; Normal weight (5th percentile $\leq$ BMI $<85$ th percentile); overweight $(85$ th percentile $\leq$ BMI $<95$ th percentile); obesity (BMI $\geq 95$ th percentile).

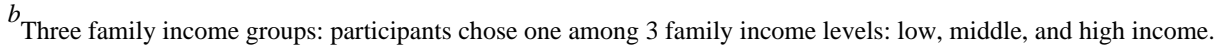


${ }^{c}$ Three education groups: both parents $<$ high school education (HS; 12 years), one of their parents $>$ college education, both parents $>$ college education.

P-value based on $\chi^{2}$ tests comparing proportions within each body weight perception status. $(* * P<0.001$ and $* * * P<0.0001)$. 


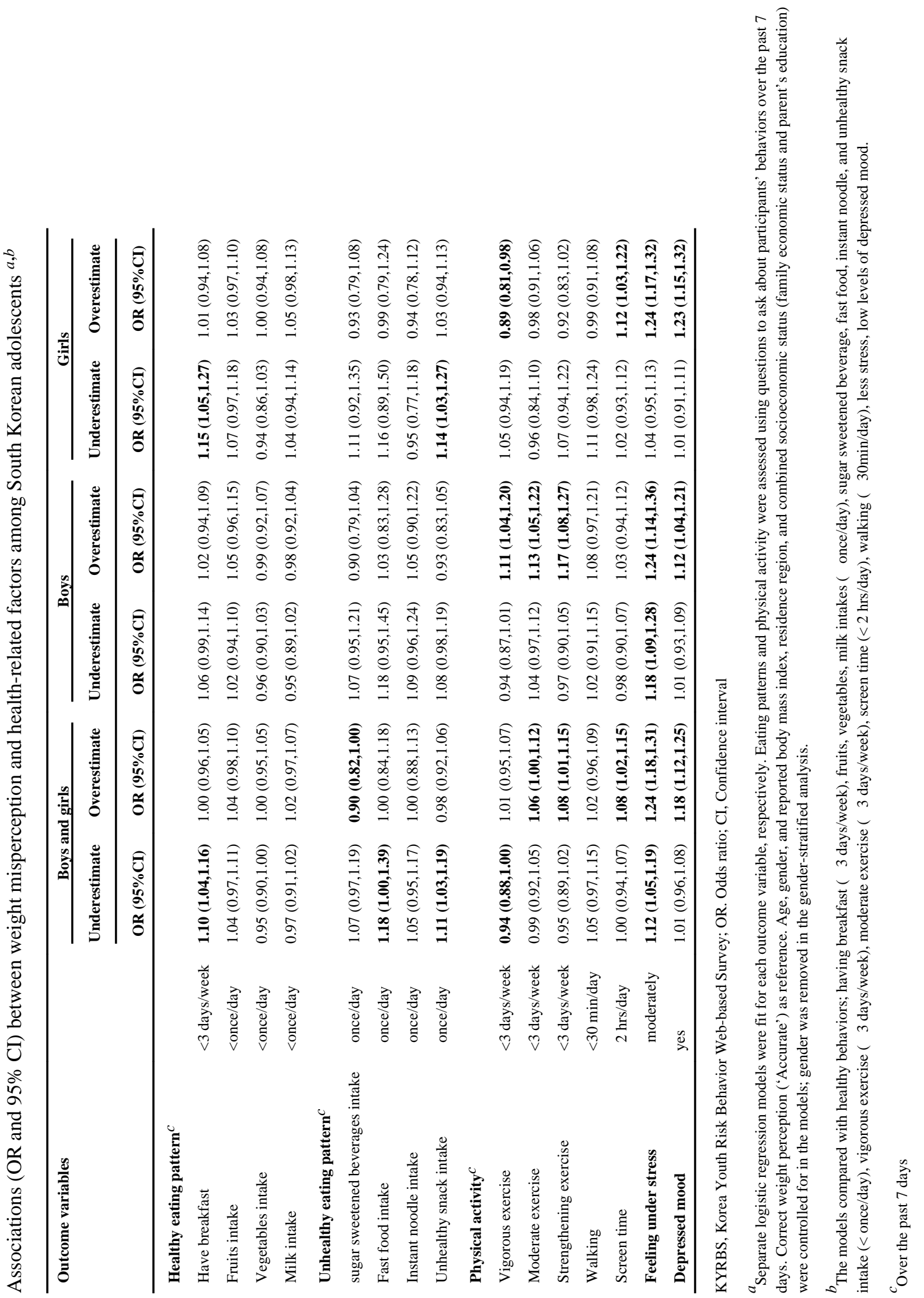

